\title{
Differential Properties of Cells in the Feline Primary Visual Cortex Providing the Corticofugal Feedback to the Lateral Geniculate Nucleus and Visual Claustrum
}

\author{
K. L. Grieve and A. M. Sillito \\ Department of Visual Science, Institute of Ophthalmology, London EC1V 9EL, United Kingdom
}

\begin{abstract}
We have examined the responses of 141 layer VI cells in the feline visual cortex. Within this group we compared the responses of a subpopulation of cells checked for connectivity by electrical stimulation in the dLGN and the visual claustrum. The antidromically identified corticogeniculate projecting cells had relatively short receptive fields, as judged from length response curves, measured quantitatively, and were located at the "short" end of the receptive field length spectrum seen in the general population. Of the 17 corticogeniculate projecting cells, $71 \%$ were $S$ type cells, which were typically monocular and directionally selective, with relatively long latencies following electrical stimulation. The remaining $29 \%$ were $C$ type cells, also directionally selective, but with a wider spread of ocular dominance preferences and shorter latencies following electrical stimulation. $S$ and $C$ type subpopulations did not differ in their receptive field lengths. The mean receptive field length for this subpopulation was $2.2^{\circ} \pm 0.27$, the shortest field being $1^{\circ}$ and the longest $5^{\circ}$. The five layer $\mathrm{VI}$ cells activated by electrical stimulation from electrodes within the dorsocaudal (visual) claustrum all had much longer receptive field lengths than the corticogeniculate population, often $10^{\circ}$ or longer and were monocular and directionally selective $S$ type cells. These data indicate that the information carried in the corticogeniculate stream (and that from layer VI directly to layer IV carried by axon collaterals) is relatively tightly focused in spatial terms whilst the less spatially focused, long receptive field output from layer VI projects to the claustrum.
\end{abstract}

[Key words: corticogeniculate, corticoclaustral, receptive field length, layer VI, corticofugal feedback, visual response properties]

Corticogeniculate projecting cells in layer VI of the primary visual cortex occupy a pivotal position in the retino-geniculostriate visual pathway, both by virtue of the very large synaptic feedback to the dorsal lateral geniculate nucleus ( $\mathrm{dLGN}$ ), and by the ascending axon collateral pathway arborizing extensively within layer IV of the cortex (Wilson et al., 1984, Katz, 1987). The traditional view of layer VI is that this layer is characterized by cells whose length summation profiles "reached very large

\footnotetext{
Received Mar. 7, 1994; Dec. 19, 1994; accepted Dec. 20, 1994.

The support of the MRC is gratefully acknowledged. We are indebted to $\mathrm{Mr}$. $\mathrm{S}$. Tassen for skilled technical assistance.

Correspondence should be addressed to A. M. Sillito, Department of Visual Science, Institute of Ophthalmology, Bath Street, London ECIV 9EL, UK.

Copyright $\mathcal{C} 1995$ Society for Neuroscience $0270-6474 / 95 / 154868-07 \$ 05.00 / 0$
}

values" (Gilbert, 1977), typically having receptive field summation lengths of $8^{\circ}$ or more (Bolz and Gilbert, 1986). However, there is no facet of the putative functional influence of layer VI cells in either layer IV of the cortex or the dLGN that requires fields of this length. For example they have been considered to have a role in the generation of endstopped receptive fields (Bolz and Gilbert, 1986) but this requires a mechanism summing over much shorter distances (Yamane et al., 1985). Indeed, work from this laboratory indicates that their direct effects in both dLGN (Murphy and Sillito, 1987; Jones and Sillito, 1991; Sillito et al., 1993) and cortex (Grieve and Sillito, 1991b; Grieve and Sillito, unpublished observations) derives from a mechanism with maximal effect at short lengths. Furthermore the majority of layer VI cells $(61 \%)$ have receptive field lengths of $4^{\circ}$ or less, and $46 \%$ of $2^{\circ}$ or less (Grieve and Sillito, 1991a). There is thus totally contradictory evidence on this matter, and it centers on the question of whether the corticogeniculate layer VI cells sending collaterals to layer IV have long receptive fields (Gilbert, 1977; Bolz and Gilbert, 1986; Bolz et al., 1989) or not. This we test in this article.

Although the corticofugal pathway to the dLGN is derived from around $50 \%$ of the cells of layer VI (Gilbert and Kelly, 1975; McCourt et al., 1986), the dLGN is not the only "subcortical" target of axons from layer VI. The dorsocaudal, or visual, claustrum, receives and reciprocates projections with almost all visual cortical areas, and between $4 \%$ and $10 \%$ of layer VI cells in primary visual cortex project to the claustrum (LeVay and Shcrk, 1981a; McCourt ct al., 1986; Katz, 1987). Intcrestingly, the receptive fields of cells in the visual claustrum have very long summation lengths (Sherk and Levay, 1981). It therefore seems logical to link the long field layer VI cells with the claustrum and the short field cells with the dLGN. Whether logical or not, this is a controversial matter and direct evidence is required. To address this issue, we have combined a quantitative study of the responses of layer VI cells with an electrophysiological analysis of their connectivity to the dLGN and visual claustrum. Although receptive field length has been the focus of our interest, we have also checked ocular dominance and direction selectivity in relation to the pattern of connectivity.

\section{Materials and Methods}

Experiments were carried out on adult cats in the weight range 2-2.5 $\mathrm{kg}$. Animals were anaesthetized with halothane (2-5\% for induction and surgery, $0.2-0.5 \%$ for maintenance, in $3: 1$ nitrous oxide and oxygen), and paralyzed $(10 \mathrm{mg} / \mathrm{kg} / \mathrm{hr}$ gallamine triethiodide $)$ EEG and ECG were continuously monitored, and end tidal $\mathrm{CO}_{2}$ maintained between 26 and $34 \mathrm{~mm} \mathrm{Hg}$, in order to maintain a state of light anesthesia. Any alteration in measured parameters commensurate with a decline in the level 
of anaesthesia were immediately compensated for by an increase in the level of halothane. Other details were as previously published (Grieve and Sillito, 1991a; Jones and Sillito, 1991).

Single units were recorded in the primary visual cortex (AP 0 to -6 ) using tungsten in glass electrodes (Merrill and Ainsworth, 1972). For electrical stimulation, pairs of tungsten stimulating electrodes $(1 \mathrm{~mm}$ exposed, $1 \mathrm{~mm}$ apart) were placed in the dLGN (AP +6-8 mm, L 810 , depth 9-13, penetration vertical), superior colliculus (SC) $(\mathrm{AP}+1-$ $2 \mathrm{~mm}, \mathrm{~L} 1.5-2.5$, depth $12-15$, penetration angled $20^{\circ}$ rostrocaudally to avoid damage to visual cortex) and visual claustrum (AP $+10-12$ $\mathrm{mm}, \mathrm{L}+10-12$, depth 9.5-13, penetration vertical), with the final positioning based on a combination of stereotaxic coordinates and visually elicited activity (background activity from stimulating electrodes for dLGN and SC; the position for the claustral electrodes was determined by recording visual activity from the claustrum with a recording electrode prior to insertion in the caudal pole of the claustrum). In some cases two pairs were placed in the dLGN. Antidromic activation of cortical cells was achieved using constant current pulses of either polarity in the range $0.03-5 \mathrm{~mA}, 0.1 \mathrm{msec}$ in duration. The stimulating electrodes in the SC served a dual function-they allowed precise identification of the entry into layer $\mathrm{V}$ of the cortex, and, more importantly, allowed exclusion of those corticotectal cells which could be antidromically activated from the dLGN by virtue of axons of passage within the dLGN, en route to the SC. Cells were considered to project to the dLGN if (1) their spikes had a fixed latency to repeated electrical stimulation of the appropriate site with a jitter of $0.3 \mathrm{msec}$ or less, (2) they faithfully followed a train of pulses of $200 \mathrm{~Hz}$, (3) their antidromic spikes collided with an orthodromic spike (usually visually elicited), (4) they were anatomically localized in layer VI, (5) they were not activated by stimulation of the $\mathrm{SC}$ electrodes, using currents more than twice that previously shown to activate corticotectal cells in overlying layer $\mathrm{V}$. Corticoclaustral cells fulfilled the first four of these criteria and were not activated from either the SC or dLGN sites.

All cells were classified by a battery of tests into $\mathrm{S}$ and $\mathrm{C}$ families, according to the criteria of Henry (Henry, 1977; Lund et al., 1979). All receptive fields were within $15^{\circ}$ of the area centralis, the vast majority within $5^{\circ}$. Summation length was assessed by drifting light bar stimuli of various lengths back and forward across the receptive field of the dominant eye, at the quantitatively derived optimum orientation. All stimuli were randomly interleaved.

At the end of the experiment animals were transcardially perfused with cold $0.9 \%$ saline, followed by $10 \%$ formaldehyde solution in normal saline and the brain blocked in stereotaxic coordinates to reconstruct both recording sites (marked with 3-5 $\mu \mathrm{A}$ for 3-5 scc), and stimulating electrode sites. Blocks were cryoprotected by immersion in $30 \%$ sucrose solution, sectioned at $50-60 \mu \mathrm{m}$ on a freezing microtome and stained with neutral red solution. All cells reported in this study were localized within layer VI, as defined by the criteria of Garey (1971).

\section{Results}

The data reported here are based on total sample of 141 layer VI cells and compare the properties of the overall sample with those of subgroups studied and identified by electrophysiological techniques as projecting to the dLGN or to the visual claustrum.

\section{Length tuning}

Corticogeniculate cells. This population comprised $12 \mathrm{~S}$ family cells $(71 \%)$ and $5 \mathrm{C}$ family cells $(29 \%)$, proportions which are not significantly different from the distribution of $\mathrm{S}$ and $\mathrm{C}$ cells within the overall population $(67 \% \mathrm{~S}$ vs $33 \% \mathrm{C}, n=119$; Grieve and Sillito 1991a). Corticogeniculate cells were located throughout the depth of layer VI. In each case a quantitatively derived length summation curve was produced for stimuli presented moving in the preferred direction at the optimum orientation. There were no cells with receptive field lengths greater than $5^{\circ}$ in length, the shortest being $1^{\circ}$. For the population of 17 cells the mean value was $2.2^{\circ}( \pm 0.27)$.

Responses typical of corticogeniculate projecting cells are illustrated by Figure 1. In this figure, the peristimulus time histograms (PSTHs) showing the averaged responses for varied bar lengths are shown beneath the length summation curve. Figure
$1 A$ illustrates an $\mathrm{S}$ type corticogeniculate projecting cell. It is immediately obvious that this cell responded robustly to the shortest stimulus tested, $0.5^{\circ}$, and had a rapid, relatively linear, rise in response magnitude to the plateau level, commencing at $2^{\circ}$, after which there was no significant alteration. The $\mathrm{C}$ type corticogeniculate cells are illustrated by the example in Figure $1 B$. Note the much higher spontaneous activity than the $S$ cells, as shown by the comparison with Figure $1 A(0$ bar length condition). Here again, the cell responded robustly to stimuli as short as $0.5^{\circ}$ and reached a plateau level by an apparent summation length of $1.5^{\circ}$, after which there was no systematic or clearly significant variation in response magnitude.

In terms of the summation lengths of their receptive fields, there was no difference between $\mathrm{S}$ and $\mathrm{C}$ family cells which projected to the LGN, and their data are pooled in Figure 2. It is strikingly obvious that the majority of the cells possess short receptive fields, as judged by previous standards (Gilbert, 1977), and that, even within the relatively restricted window of RF lengths up to $5^{\circ}$, the vast majority of cells were clustered around $1.5-2^{\circ}$. This histogram should be compared to the inset to Figure 2 , showing the distribution of receptive field lengths for the population of 141 cells. Receptive fields lengths ranged between 0.5 to longer than $10^{\circ}$. Some $62 \%$ of these cells had receptive field lengths of $4^{\circ}$ or less, $27 \%$ had receptive field lengths of $2^{\circ}$ or less, with only $17 \%$ having the very long fields of $10^{\circ}$ or more, thus confirming our previous report (Grieve and Sillito, 1991a).

The latencies of the responses to electrical stimulation are shown in Figure 3. All five $\mathrm{C}$ cells had latencies of less than 3 $\mathrm{msec}$, while the range of latency values for the $\mathrm{S}$ cell population was very large (up to $32 \mathrm{msec}$ ), with no $S$ cell with a latency less than $2 \mathrm{msec}$. Although conduction velocities were not measured, the very long latencies of some of the $S$ cell group is suggestive of very slow conduction. Certainly, the $\mathrm{C}$ family cells seem to have much faster conduction velocities than the vast majority of the $S$ family cells. These findings are in keeping with earlier work of Harvey (1980).

Corticoclaustral cells. Electrical stimulation of the dorsocaudal claustrum identified five layer VI cells as corticoclaustrally projecting. The properties of this group of cells were very similar. All five were $S$ type, with varied and long latencies from stimulation of the claustrum of between 8 and $32 \mathrm{msec}$. All five exhibited tight orientation tuning. These cells all showed similar length summation, summating over considerably greater distances than found for any corticogeniculate projecting cell. The minimum receptive field length found was $8^{\circ}$ (one cell), while the maximum could not be measured because the longest stimuli used was $10^{\circ}$ (four cells). A typical length summation curve is shown in Figure 4. In complete contradistinction to the receptive fields of corticogeniculate cells (see Fig. 1), the receptive field of the corticoclaustrally projecting cell had a minimum summation length of $10^{\circ}$ and was poorly responsive to stimuli of lengths encompassing almost the entire range of summation lengths we have shown for the corticogeniculate projecting cells. It is clear that this cell would fall into the category of long field layer VI cells which constituted only $17 \%$ of our overall sample (see inset to Fig. 2).

\section{Ocular dominance and direction selectivity}

We made a detailed assessment of ocular dominance in 85 of the 141 layer VI cells using the seven point scale of Hubel and Wiesel (1962) to check the incidence of binocularity. The distributions are shown in Figure 5. To highlight the subdivision 
A
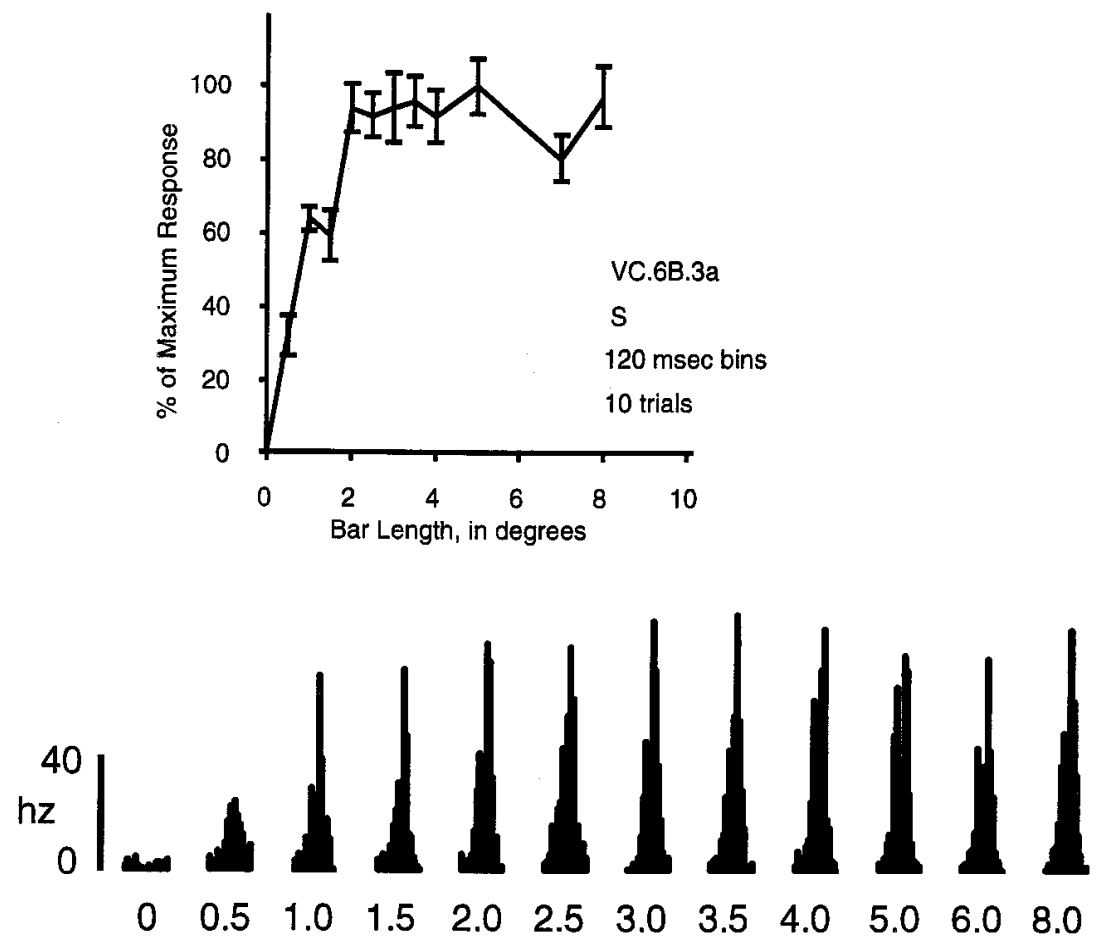

Figure 1. A, The length response

B curve for a layer VI $S$ type corticogeniculate projecting cell. Values have been normalized to the maximum response $(100 \%)$, and are shown \pm 1 SEM, after subtraction of the background firing rate (measured from the zero bar length condition). Beneath, individual PSTHs from which the tuning curve was derived. Only responses to stimuli moved in the preferred direction of motion are shown. Stimulus length in degrees is given beneath individual PSTHs. Bin size and the number of stimulus repetitions are given in the legend at the top right of the tuning curve. This cell had an antidromic lalency from dLGN stimulation of 14 msec, was directionally selective and was classified as ocular dominance group 7. $\boldsymbol{B}$, Length response curve and PSTHs for a layer VI C type corticogeniculate projecting cell. Details are as given for $A$. This cell had an antidromic latency from dLGN stimulation of $2 \mathrm{msec}$, was directionally specific and was classified as ocular dominance group 1.
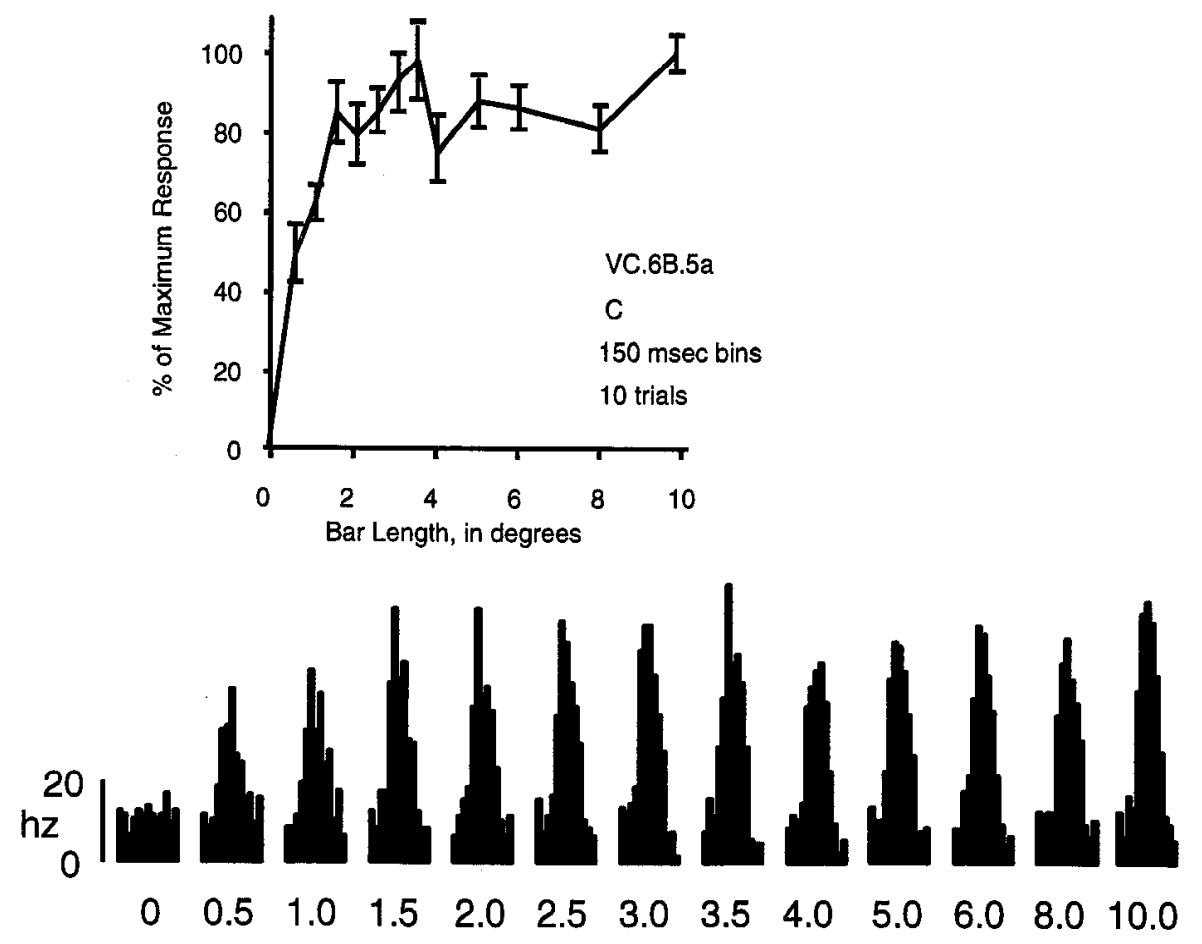

into binocular and monocular cells the contralateral and ipsilateral groups have been combined with group 1 added to 7, 2 to 6 and the strongly binocular groups 3, 4, 5 displayed together. In the general population binocular and monocularly dominated cells were more or less equally represented in the $S$ and $C$ cell families. However, in the corticogeniculate group there was a preponderance of monocular cells in the S cell sample with $71 \%$ in groups 1 and 7, and 29\% in groups 2 and 6, and none in groups 3,4 , or 5 . On the other hand, the $C$ cells population did not differ from the general population. The responses of all five corticoclaustral cells were also heavily dominated by one eye, with none in groups 3,4 , and 5 . 


\section{Cortico-geniculate cells}

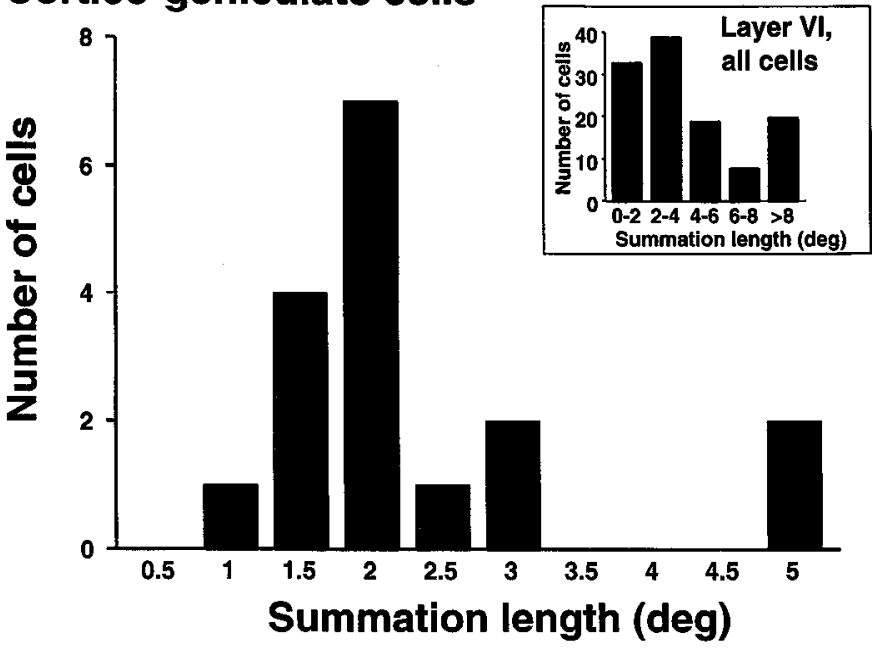

Figure 2. Summary histogram of the receptive field lengths of the population of 17 corticogeniculate projecting cells. For clarity $\mathrm{S}$ and $\mathrm{C}$ cells have not been separated-there was no significant differences in the means for the two populations. It should be noted that the receptive field length was judged to be the point on the length response curve at which the plateau level of firing was reached - this is not a measure of minimum response field (Barlow et al., 1967). Inset, Bar histogram of receptive field lengths for the population of 141 layer VI cells. Cells have been grouped according to field length, judged from the quantitatively derived length tuning curves.

In our total sample of layer VI cells, we observed that a significant proportion of the population were directionally selective for a correctly oriented stimulus. This is illustrated in the histogram in Figure 6 . Some $85 \%$ of the general population were selective for the direction of stimulus motion, having a ratio of responses to the preferred versus the non-preferred direction of $3: 2$ or greater. Indeed some $39 \%$ were directionally specific, that is, responded only to one direction of movement of the appropriately oriented bar-these cells were unresponsive to movement in the "non-preferred" dircction. Morc intcrestingly, in our sample of cells projecting to the dLGN, there is also a significant

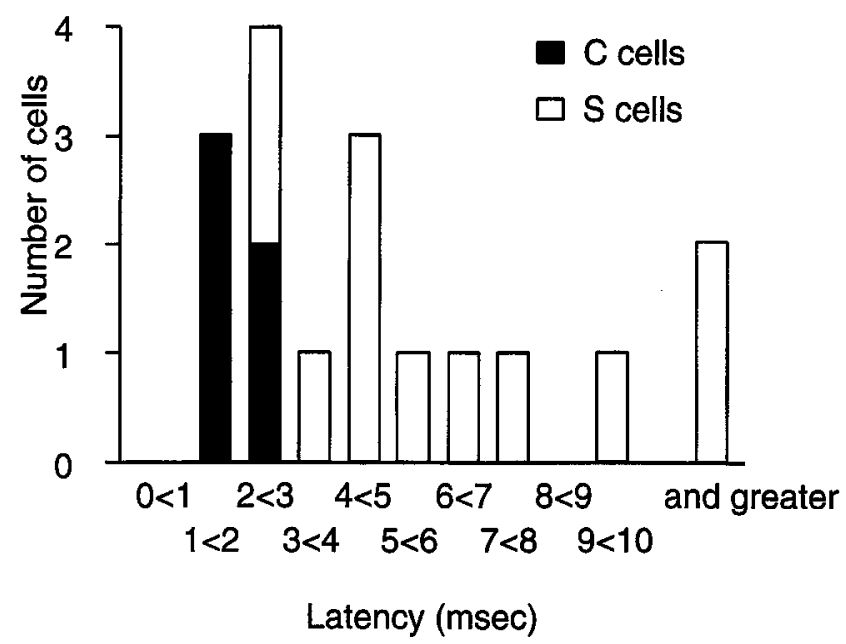

Figure 3. Histogram summarizing the antidromic latencies of the population of 17 corticogeniculate projecting cells. The $\mathrm{x}$-axis gives the latency to firing in milliseconds, following stimulation within the dLGN. Solid symbols represent $\mathrm{C}$ type cells and open symbols $\mathrm{S}$ type cells.
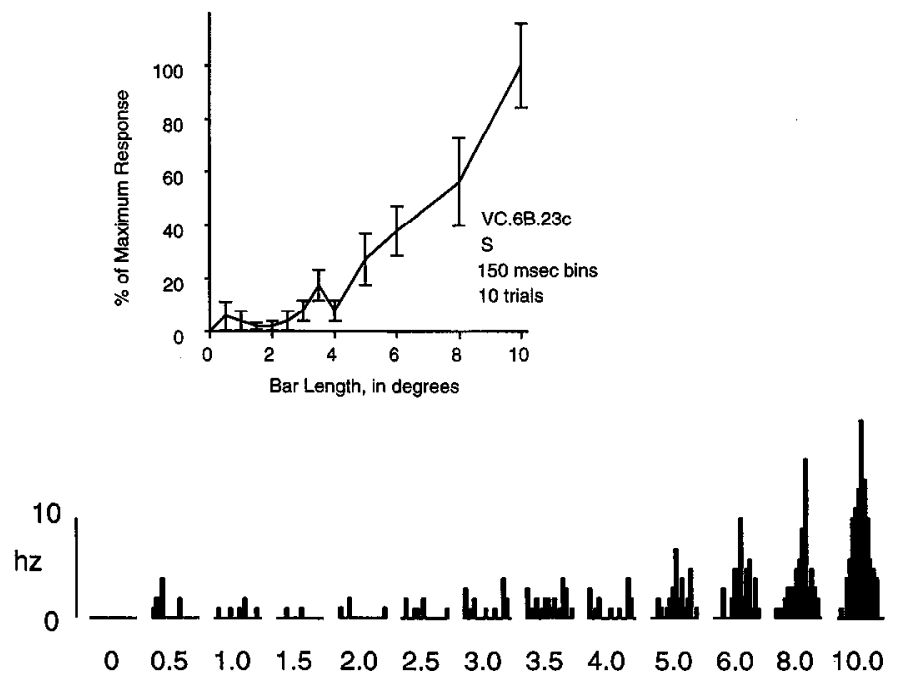

Figure 4. Length tuning curve and PSTHs for a corticoclaustrally projecting cell. This cell had an antidromic latency from visual claustrum stimulation of $14 \mathrm{msec}$, and was directionally specific. Other details are as for Figure 1.

degree of direction selectivity. In fact, 9/17 (53\%) of these cells were directionally specific in their responses, including both $\mathrm{S}$ and $\mathrm{C}$ type cells. Of the remainder, five were directionally selective, ie responding to both directions of motion, but having a clear preference for responses in one direction, and three were

General population
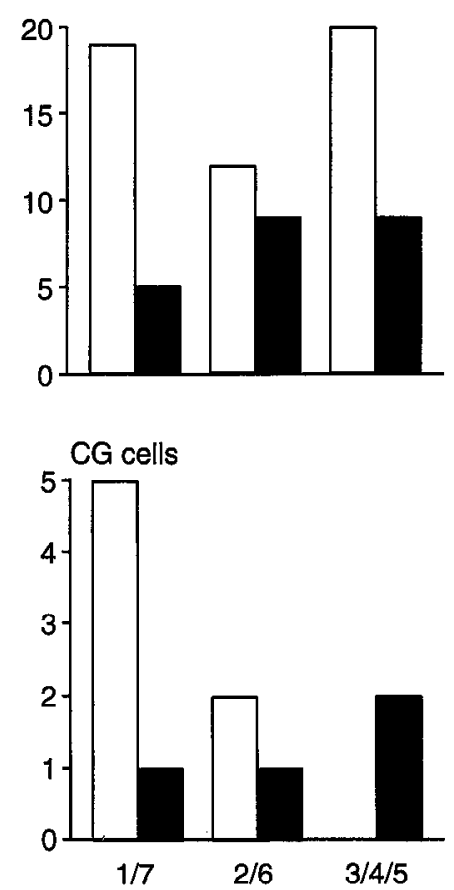

Figure 5. Top, Histogram summarizing ocular dominance for 74 of the 119 layer VI cells. As in Figure 3, solid symbols represent $C$ type cells and open symbols $\mathrm{S}$ type cells. For clarity, ocular dominance measured on the 7 point scale of Hubel and Wiesel (1962) has been contracted (see text) to clarify the comparison of monocular versus binocularly responding cells, with the most monocular groups to the left of the histogram and the most binocular to the right. Bottom, Histogram detailing the ocular dominance of 11 of the 17 corticogeniculate cells, displayed as in the top panel. 


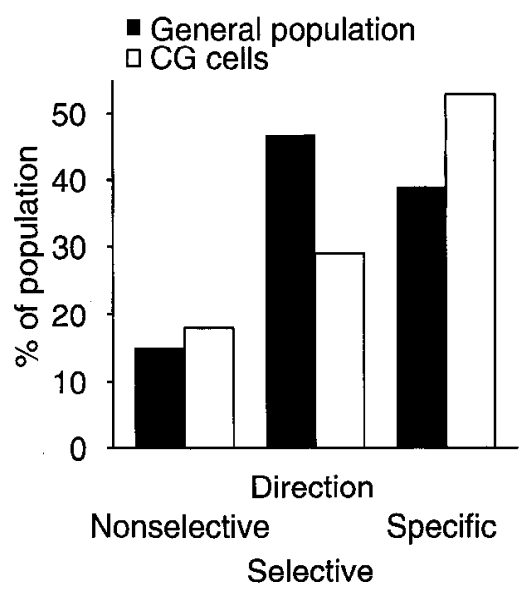

Figure 6. Direction selectivity of the population of corticogeniculate cells (solid symbols) compared to the large population of layer VI cells without identified targets (open symbols). In each population, $\mathrm{S}$ and $\mathrm{C}$ family cells have been concatenated. To quantify direction selectivity, a directionality index (DI) was calculated from the responses to a correctly oriented long bar stimulus, with DI $=[$ (response to preferred direction - response to nonpreferred direction)/response to preferred direction] $\times 100$. Cells with DI $<33$ (i.e., $0-32$ ) were regarded as not selective, with $32<\mathrm{DI}<81$ as directionally selective (i.e., a response to movement in the preferred more than $50 \%$ greater than the nonpreferred direction, Duysens et al., 1987) and DI $>80$ directionally specific.

not selective for direction of motion of the stimulus. It is immediately obvious that selectivity for stimulus direction is characteristic of the majority of layer VI cells, and the majority of our sample of corticogeniculate cells. Similarly, in our sample of five corticoclaustrally projecting cells, the majority were directionally selective, the example shown in Figure 4, along with one other, being directionally specific.

\section{Discussion}

A primary finding from our data is that the layer VI cells identified as projecting to the $\mathrm{dLGN}$, and hence sending collaterals to layer IV (Katz, 1987) have short receptive summation lengths, with a mean length of $2.2^{\circ}$. This is in full accord with the summation lengths that seem to fit best the functional influences of layer VI cells identified in our own work (Murphy and Sillito, 1987; Grieve and Sillito, 1991b; Jones and Sillito, 1991). The mean summation length of the fields projecting to the dLGN is somewhat shorter than that for the population as a whole, but even the values of the population as a whole are much shorter than those previously considered to represent layer VI (Gilbert, 1977; Bolz and Gilbert, 1986; Bolz et al., 1989).

There are several interesting anatomical observations relevant to our findings, of which one of the most interesting is that of Katz and coworkers (Katz et al., 1984; Katz, 1987). They have reported that within layer VI the morphology of the majority of corticogeniculate projecting cells is quite distinct, such that characteristically these cells have apical dendrites which arborize in layer IV and also have axon collaterals which arborize extensively in layer IV. Cells which project to the visual claustrum, on the other hand, lack such apical dendritic arbors and axon collaterals, instead having an axon collateral which extends laterally within layer VI up to $1 \mathrm{~mm}$. This suggests that the corticogeniculate projecting cell may also have intimate involvement in information processing between layer VI and layer IV, the primary geniculate receiving layer. Such vertically directed, intracolumnar processes are in keeping with the relatively restricted receptive field dimensions we have now reported. Indeed, we have recently shown that pharmacological blockade of layer VI results in the loss of a direct facilitatory input to hypercomplex cells in overlying layer IV, which in some cases serves to enhance the stimulus specificity of these cells to short stimuli (Grieve and Sillito, 1991b). Our findings within the cortex (Grieve and Sillito, 1991b) support the view that the drive from layer VI to layer IV hypercomplex cells (and hence to overlying layers II/III hypercomplex cells) is mainly excitatory in nature, in keeping with recent anatomical observations (Somogyi 1989) and earlier electrophysiological data (Ferster and Lindstrom, 1985a,b). A drive via inhibitory interneurons has also been observed to non-length-selective layer IV cells, perhaps receiving input from more remote cortical locations (Grieve and Sillito, unpublished observations).

On the basis of receptive field structure, our population of corticogeniculate cells could clearly be divided into two subpopulations - the S $(71 \%)$ and $\mathrm{C}$ type $(29 \%)$ cells, which differed in their ocular dominance and latencies to electrical stimulation. Speculatively, it is interesting to note that Katz (1987) describes a dichotomy in his population of anatomically defined layer VI corticogeniculate cells, with the majority, his type 1, some $80 \%$, being as described above, with extensive dendritic and axonal collaterals within layer IV, noted for the preponderance of $S$ type receptive fields (Gilbert, 1977). The remaining $20 \%$, his type 2 , were more restricted in their dendritic and axonal arbors, which had apical dendrites and axonal collaterals which rarely reached above layer $\mathrm{V}$, a layer often charactcrized by the presence of directionally selective binocular $\mathrm{C}$ type receptive fields (Palmer and Rosenquist, 1974; Gilbert, 1977; Henry et al., 1979). It is therefore plausible that our S family cells represent type 1 and our $\mathrm{C}$ family cells represent the type 2 cells of Katz (1987).

At the level of the dLGN, anatomical information regarding targets of cortical input is contradictory, suggesting on the one hand that input from the cortex is predominantly mediated via inhibitory interneurons (Weber et al., 1989) and on the other that such influence is in the main directly to relay cells (Montero, 1991). One line of physiological evidence from this laboratory supports an input to the dLGN mediated via inhibitory interneurons, producing a negative feedback sensitive to orientation discontinuities which serves to minimize dLGN output to the cortex during the presentation of coherent elongate stimuli (Sillito et al., 1993), and enhances the relative responsiveness of the cortex to discontinuities present in a visual stimulus in a way which facilitates perceptual pop-out.

The strong representation of directional selectivity in the corticogeniculate cells is interesting, suggesting that this response parameter is important to the functional logic of this system. Indeed, this property has also been reported to be common in layer VI cells, particularly $S$ type, in the macaque (Hawken et al., 1988). To date there has been no demonstration of a cortically dependent direction bias in dLGN cell responses (Innes and Sillito 1994). However, it has recently been demonstrated that the descending influence from the cortex seems to bring cells in the dLGN into synchronous firing when driven by oriented moving stimuli (Sillito et al., 1994). This synchronicity is dependent upon the exact coactivation of spatially separated receptive fields by an appropriately oriented contour and may serve to enhance the gain of the input from the convergent $\mathrm{dLGN}$ cell synapses generating the orientation bias of cortical 
cells. The presence of directional as well as orientation bias in the responses of feedback cells allows for an organized feedforward influence via collaterals to the subset of dLGN neurons which will next lie in the path of the moving stimulus. This "anticipatory" feedforward facilitation could act to synchronize their dischargc and thus produce a wave of enhanced gain in the path of the moving oriented contour.

In complete contradistinction to the corticogeniculate cell receptive fields, cells in layer VI which project to the visual claustrum have very long receptive fields. This finding is at first sight not surprising. Cells within the visual claustrum, receiving input essentially only from visual cortices, have been reported to have very long receptive fields, with fields up to $40^{\circ}$ in length (Creutzfeldt et al., 1980; LeVay and Sherk, 1980; Sherk and LeVay, 1981) and so a long field input from area 17 is quite likely. The monocularly dominated, highly directionally selective $S$ type corticoclaustral receptive fields suggest that this pathway may subserve a dual role. First, it will convey information to the claustrum, which, however, contains cells with binocular $\mathrm{C}$ type receptive fields not selective for stimulus direction, integrating inputs from almost all visual cortical areas (LeVay and Sherk, 1981a,b; Sherk and LeVay, 1981). Secondly, corticoclaustral cells have a capacity for intracortical information processing, within area 17, by virtue of their local axon collaterals. These collaterals are known to extend within layer VI of area 17 for up to $1 \mathrm{~mm}$, with vertical branches arborizing in lower layer $\mathrm{V}$ (Katz, 1987), and here the corticoclaustral cells may utilize the more specific receptive field information on ocular dominance, spatial phase and direction of stimulus motion at a local level within the cortex, where such properties are common.

The range of receptive field lengths of layer VI cells fall over a wide spectrum, ranging from the very short, less than $1^{\circ}$, to the very long, greater than $10^{\circ}$ (Grieve and Sillito, 1991a). The data presented here describes the functional connectivity of cells which occupy the two ends of the spectrum. Nevertheless, on the basis of arithmetic alone, it is necessary to take note of other cells with receptive field dimensions which are not covered by those projecting to dLGN or claustrum. These are cells whose receptive field lengths fall between the two extremes. It is known that output from layer VI is directed to other targets-ipsilateral and contralateral areas 18 and 19 receive an input from layer VI of area 17 (McCourt et al., 1986), as does ipsilateral suprasylvian visual cortex (Einstein, 1988). Furthermore, there is evidence to suggest that a substantial proportion of layer VI cells do not have an efferent axon, (perhaps some 20\%), instead having exclusively intracortical axons, with such cells having the morphology either of the corticogeniculate or corticoclaustral cell types (Katz, 1987). Thus the spectrum of receptive field lengths found in layer VI may in fact relate to a spectrum of both intracortical (within and without area 17), and subcortical targets. The data we have presented here, for the first time, clearly differentiates the likely sphere of influence of two of the output pathways from layer VI of the primary visual cortex. Output to the visual claustrum is from cells with very long receptive fields and thus lacks a discrete spatial focus. In contradistinction, output to the dLGN, and to the overlying layer IV, is from cells with very much shorter receptive fields, among the shortest found in layer VI and is thus sharply spatially focused.

\section{References}

Barlow HW, Blakemore C, Pettigrew JD (1967) The neural mechanism of depth discrimination. J Physiol (Lond) 193:327-342.
Bolz J, Gilbert CD (1986) Generation of end-inhibition in the visual cortex. Nature 320:362-365.

Bolz J, Gilbert CD, Wiesel TN (1989) Pharmacological analysis of cortical circuitry. Trends Neurosci 12:292-296.

Creutzfeldt O, Mucke L, Bang-Olsen R (1980) Responses of claustral neurones to visual stimulation. Exp Brain Res 41:A10.

Duysens J, Maes H, Orban GA (1987) The velocity dependence of direction selectivity of visual cortical neurones in the cat. J Physiol (Lond) 387:95-113.

Einstein G (1988) Intracellular injection of Lucifer yellow into cortical neurons in lightly fixed sections and its application to human autopsy material. J Neurosci Methods 26:95-103.

Ferster D, Lindstrom S (1985a) Augmenting responses evoked in area 17 of the cat by intracortical axon collaterals of cortico-geniculate cells. J Physiol (Lond) 367:217-232.

Ferster D, Lindstrom S (1985b) Synaptic excitation of neurones in area 17 of the cat by intracortical axon collaterals of cortico-geniculate cells. J Physiol (Lond) 367:233-252.

Garey LJ (1971) A light and electron microscopic study of the visual cortex of the cat and monkey. Proc R Soc Lond [Biol] 179:21-40.

Gilbcrt CD (1977) Laminar differences in receptive field properties in cat primary visual cortex. J Physiol (Lond) 268:391-421.

Gilbert CD, Kelly JP (1975) The projection of cells in the different layers of the cat's visual cortex. J Comp Neurol 163:81-106.

Grieve KL, Sillito AM (1991a) Length summation properties of layer VI cells in the visual cortex and hypercomplex cell end zone inhibition. Exp Brain Res 84:319-325.

Grieve KL, Sillito AM (1991b) A re-appraisal of the role of layer VI of the visual cortex in the generation of cortical end inhibition. Exp Brain Res 87:521-529.

Harvey AR (1980) A physiological analysis of subcortical and commissural projections of areas 17 and 18 of the cat. J Physiol (Lond) 302:507-534

Hawken MJ, Parker AJ, Lund JS (1988) Laminar organization and contrast sensitivity of direction-selective cells in the striate cortex of the old world monkey. J Neurosci 8:3541-3548.

Henry GH (1977) Receptive field classes of cells in the striate cortex of the cat. Brain Res 133:1-28.

Henry GH, Harvey AR, Lund JS (1979) The afferent connections and laminar distributions of cells in the cat striate cortex. J Comp Neurol 187:725-744.

Hubel DH, Wiesel TN (1962) Receptive fields, binocular interaction and functional architecture in the cat's visual cortex. J Physiol (Lond) 160:106-154.

Jones HE, Sillito AM (1991) The length response properties of cells in the feline dorsal lateral geniculate nucleus (dLGN). J Physiol (Lond) 444:329-348.

Jones HE, Sillito AM (1994) Directional asymmetries in the lengthresponse protiles of cells in the feline dorsal lateral geniculate nucleus. J Physiol (Lond) 479:475-486.

Katz LC (1987) Local circuitry of identified projection neurons in cat primary visual cortex brain slices. J Neurosci 7:1223-1249.

Katz LC, Burkhalter A, Dreyer W (1984) Fluorescent latex microspheres as a retrograde neuronal marker for in vivo and in vitro studies of visual cortex. Nature 310:493-500.

LeVay S, Sherk H (1980) The cortico-claustral loop. Exp Brain Res 41:A8-A9.

LeVay S, Sherk H (1981a) The visual claustrum of the cat. I. Structure and connections. J Neurosci 1:956-980.

LeVay S, Sherk H (1981b) The visual claustrum of the cat. II. The visual field map. J Neurosci 1:981-992.

Lund JS, Henry GH, McQueen CL, Harvey AR (1979) Anatomical organization of the primary visual cortex (area 17) of the cat. A comparison with area 17 of the macaque monkey. J Comp Neurol 184:599-618.

McCourt ME, Boyapati J, Henry GH (1986) Layering in lamina 6 of cat striate cortex. Brain Res 368:181-185.

Merrill EG, Ainsworth A (1972) Glass-coated tungsten microelectrodes. Med Biol Eng 10:662-672.

Montero VM (1991) A quantitative study of synaptic contacts on interneurons and relay cells of the cat lateral geniculate nucleus. Exp Brain Res 86:257-270.

Murphy PC, Sillito AM (1987) Cortico-fugal feedback influences the generation of length tuning in the visual pathway. Nature 329:727729. 
Palmer LA, Rosenquist AC (1974) Visual receptive fields of single cortical units projecting to the superior colliculus in the cat. Brain Res 67:27-42.

Sherk H, LeVay S (1981) The visual claustrum of the cat. III. Receptive field properties. J Neurosci 1:993-1002

Sillito AM, Cudeiro J, Murphy PC (1993) Orientation sensitive elements in the corticofugal influence on centre-surround interactions in the dorsal lateral geniculate nucleus. Exp Brain Res 93:6-16.

Sillito AM, Jones HE, Gerstein GL, West DC (1994) Feature-linked synchronization of thalamic relay cell firing induced by feedback from the visual cortex. Nature 369:479-482.

Somogyi P (1989) Synaptic organization of GABAergic neurons and
$\mathrm{GABA}_{\mathrm{A}}$ receptors in the lateral geniculate nucleus and visual cortex. In: Neural mechanisms of visual perception (Lam DKT, Gilbert CD, eds), pp 35-62. Texas: Portfolio.

Weber AJ, Kalil RE, Behan M (1989) Synaptic connections between cortico-geniculate axons and interneurons in the dorsal lateral geniculate nucleus of the cat. J Comp Neurol 289:156-164.

Wilson JR, Friedlander MJ, Sherman SM (1984) Fine structural morphology of identificd X- and X-cclls in the cat's lateral geniculate nucleus. Proc R Soc Lond [Biol] 221:411-436.

Yamane S, Maske R, Bishop PO (1985) Properties of end-zone inhibition of hypercomplex cells in cat striate cortex. Exp Brain Res 60: 200-203 